\title{
"NÃO TOQUE EM MIM NA SEGUNDA-FEIRA": DIFERENÇA, ABJEÇÃO E IDENTIDADE EM UM PROJETO DE EXTENSÃO NO CAMPUS PANTANAL DA UNIVERSIDADE FEDERAL DE MATO GROSSO DO SUL
}

\section{Resumo}

Este relato de experiência foca no projeto de extensão "Encontros de Leituras Sobre Gênero e Sexualidade", realizado no Campus Pantanal, da Universidade Federal de Mato Grosso do Sul, em 2014 e 2015. A coordenação da ação foi realizada por acadêmica do curso de psicologia, sob a minha orientação. Aqui apresento o histórico e o desenvolvimento das atividades, assim como os efeitos da visibilidade dos encontros no contexto local. Discuto, no viés pós-estruturalista, o quanto as questões de gênero e sexualidade, além de serem temas do projeto, também nos ajudam a avaliar a baixa assiduidade das trinta e seis pessoas que frequentaram esporadicamente os quinze encontros. A aversão à abjeção, isto é, ao não reconhecimento positivo das performances de gênero e das sexualidades que não correspondem necessariamente à matriz de inteligibilidade “"sexo” = gênero $=$ desejo" é apontada como um fator importante para a avaliação da experiência e do próprio contexto cultural da fronteira Brasil-Bolívia.

Palavras-Chave: Diferença; Abjeção; Identidade; Fronteira; Extensão

\section{INTRODUÇÃO}

\footnotetext{
${ }^{1}$ Doutor em Ciências Sociais, professor do Mestrado em Educação do Campus Pantanal da Universidade Federal de Mato Grosso do Sul (CPAN/UFMS) e do Centro de Ciências Humanas e Sociais da mesma instituição (CCHS - Campo Grande). Endereço: Rua XV de Novembro, 230, apto 121. Centro. Campo Grande -MS, Brasil. CEP 79002-140. E-mail: duque_hua@yahoo.com.br
} 
Este artigo, em forma de relato de experiência, reflete os resultados finais do projeto de extensão "Encontros de Leitura Sobre Gênero e Sexualidade", realizado no Campus Pantanal da Universidade Federal de Mato Grosso do Sul, na cidade de Corumbá, nos anos de 2014 e 2015. A coordenação do projeto foi da acadêmica Daniela Peño Paiva, do curso de Psicologia, sob a minha orientação. Eu e a acadêmica participamos de todos os encontros presenciais.

As reflexões aqui se fundamentarão nos dados presentes no relatório final (PAIVA, 2016), em um artigo recentemente publicado de minha autoria em que discuto parte destas experiências (DUQUE, 2016), nos próprios textos das autoras e autores lidos e estudados nos encontros e em outras pesquisadoras e pesquisadores da área do gênero e da sexualidade pertencentes ao campo teórico feminista, pós-colonial e queer. Essa postura teórica altera o foco de uma exclusiva preocupação com a opressão e libertação dos sujeitos para a análise das práticas institucionais, da produção dos conhecimentos sobre a sexualidade, e do modo como eles organizam a vida social. A Teoria Queer ${ }^{2}$ atenta, em particular, para o modo como esses conhecimentos e práticas sociais oprimem diferenças (SEIDMAN, 1996, p. 13). Segundo Jagose (1996), o queer acessa uma teorização de identidade pós-estruturalista, apontando para uma crescente consciência das limitações das categorias identitárias em termos de política de representação.

No entanto, quando me refiro às diferenças, tomo-as como não sendo sempre um marcador de hierarquia e opressão. "É uma questão contextualmente contingente saber se a diferença resulta em desigualdade, exploração e opressão ou em igualitarismo, diversidade e formas democráticas de agência política” (BRAH, 2006, p. 374). Esse ponto está diretamente relacionado, portanto, com questões identitárias, compreendendo aqui a identidade nos termos de Brah, isto é, como uma "multiplicidade relacional em constante mudança", sem deixar de compreender que "no curso desse fluxo, as identidades assumem padrões específicos, como num caleidoscópio, diante de conjuntos particulares de circunstâncias pessoais, sociais e históricas" (2006, p. 371).

Além desta conceituação sobre diferença e identidade, o projeto em questão discutiu gênero a partir das afirmações de Bento, quanto ao seu estudo da experiência transexual no contexto brasileiro:

\footnotetext{
${ }^{2} \mathrm{O}$ queer é uma categoria local estadunidense que pode significar excêntrico, esquisito, diferente; bem como o pervertido sexual, marginal, estigmatizado ou anormal. Antes de ser usado como uma categoria teórica, o queer foi empregado nos contextos do movimento social estadunidense voltado contra as propostas das organizações e do movimento gay que buscavam garantir direitos civis assimilacionistas e moralizantes.
} 
DUQUE, T.

O gênero só existe na prática, na experiência e sua realização se dá mediante reiterações cujos conteúdos são interpretações sobre o masculino e o feminino, em um jogo, muitas vezes contraditório e escorregadio, estabelecido com as normas de gênero. $\mathrm{O}$ ato de pôr uma roupa, escolher uma cor, acessórios, o corte de cabelo, a forma de andar, enfim, a estética e a estilística corporal, são atos que fazem o gênero. Que visibilizam e estabilizam os corpos na ordem dicotomizada dos gêneros. Também os/as homens/mulheres biológicos/as se fazem na repetição de atos que se supõe que sejam os mais naturais. A partir de uma citacionalidade de uma suposta origem, transexuais e não transexuais igualam-se (BENTO, 2006, p. 228).

Já a sexualidade aqui, é compreendida segundo Foucault (2007), como um dispositivo histórico de poder, que por meio de saberes e práticas sociais a ele vinculadas, procura ordenar os corpos. Um dispositivo é um conjunto heterogêneo de discursos e práticas sociais, uma verdadeira rede que se estabelece entre elementos tão diversos como a literatura, enunciados científicos, instituições e proposições morais. Isto é, não é a realidade subterrânea que se apreende com dificuldade, mas a

grande rede da superfície em que a estimulação dos corpos, a intensificação dos prazeres, a incitação ao discurso, a formação dos conhecimentos, o reforço dos controles e das resistências, encadeiam-se uns aos outros, segundo algumas grandes estratégias de saber e de poder (FOUCAULT, 2007, p.117).

Assim, esses conceitos direcionaram as escolhas dos textos e a reflexão nos encontros, como ficará claro neste relato, uma vez que deram o tom dos efeitos da visibilidade do projeto no contexto local.

\section{O PROJETO E SEUS OBJETIVOS: UMA RÁPIDA CONTEXTUALIZAÇÃO}

Este projeto de extensão foi um desdobramento do plano de trabalho iniciado em 2013, intitulado "Grupo de Estudos sobre Gênero, Família, Sexualidade e Direitos Humanos", vinculado ao projeto "guarda-chuva" do Prof. Esp. Aurélio Tomaz Silva Briltes, intitulado "Direito à prevenção ao uso indevido de álcool e drogas". Naquele ano, eu ainda não era professor da Universidade Federal de Mato Grosso do Sul, não tinha contato com a acadêmica e nem mesmo com a realidade local do Campus Pantanal.

Em 2014, quando assumi o cargo de professor universitário em Corumbá, a pedido da acadêmica e considerando a minha área de estudos e pesquisas, propus dar um direcionamento voltado à formação discente, assim como de pessoas da comunidade não 
acadêmica, para uma interpretação teórico-crítica das normas e convenções sociais que envolvem as questões de gênero e da sexualidade, ampliando as reflexões para além da demanda da família. Assim, Daniela finalizou as atividades do plano em andamento desde 2013 e iniciamos o planejamento, construção e execução do projeto de extensão em questão.

Os objetivos do projeto foram o de reunir acadêmicas, acadêmicos e pessoas da comunidade que demonstravam interesse na temática do gênero e da sexualidade; favorecer a reflexão crítica a respeito das questões do gênero e da sexualidade na comunidade acadêmica e também na comunidade em geral; incentivar a leitura; promover reflexões que gerassem ações concretas para diminuir a vulnerabilidade de pessoas tidas como "muito diferentes" em termos de gênero e sexualidade; incentivar novas pesquisas na área do gênero e da sexualidade e divulgar resultados de pesquisas com esta temática para a comunidade não acadêmica.

As leituras dos encontros foram conduzidas por mim sob a forma de seminários dialogados, na maior parte das vezes, quinzenalmente aos sábados à tarde, mas também realizamos alguns poucos encontros durante a noite, em dias da semana. As pessoas participantes tinham acesso antecipadamente à bibliografia para poderem contribuir com as reflexões. O contexto local foi sempre objeto de reflexão e análise crítica a partir das discussões teóricas, especificamente no tocante à realidade dos grupos mais vulneráveis. As considerações, partindo da produção teórica do próprio grupo, também foram bem-vindas.

Avaliamos que todos os objetivos citados acima foram concretizados, com maior destaque à promoção de reflexões que geraram ações concretas, apontamentos que impactassem na diminuição da vulnerabilidade de pessoas percebidas como "muito diferentes" ao se tratar de gênero e sexualidade. Um exemplo disso é o fato de ter ocorrido a participação constante de uma funcionária pública da Prefeitura Municipal de Corumbá, o que, segundo ela, foi uma experiência de capacitação para lidar com algumas especificidades do seu trabalho, que antes não sabia como fazer (a mesma trabalha na Secretaria Municipal de Educação, em ações ligadas às práticas de inclusão escolar). Além disso, a visibilidade deste projeto no campus favoreceu o diálogo de Daniela - a coordenadora desta atividade de extensão - com uma professora de sua graduação que, considerando o que havíamos estudado nos encontros e, somando aos interesses temáticos desta professora, incluiu em uma das disciplinas (Psicologia e Políticas Públicas) as questões de gênero e sexualidade, impactando deste modo numa formação mais qualificada destes e destas profissionais ao tratar de questões em torno da temática desse projeto. 
DUQUE, T.

Todavia, com exceção da coordenadora da ação e deste professor orientador, apesar dos incentivos, novas atividades e iniciativas propostas na área do gênero e da sexualidade não foram iniciadas no período de duração deste projeto de extensão. Com base nesta experiência, destaco algumas delas. Tanto eu, como Daniela, participamos com apresentação de trabalho, em formato de relato de experiência, no "II Simpósio sobre Gênero e Sexualidade - Corpos Vigiados e Laicidade do Estado", organizado pelo Laboratório de Estudos sobre Violência, Gênero e Sexualidade da UFMS (Campo Grande). A acadêmica Daniela também teve um artigo científico aprovado para apresentação oral no "XIII Encontro Nacional em Universidades sobre Diversidade Sexual e de Gênero - Radicalizando as Lutas - O Enfrentamento Cotidiano ao CIS-TEMA em Tempos de Crise" (ENUDSG 2015). Também apresentei parte do que vivenciamos neste projeto no Encontro da ANPED Centro-Oeste, realizado na cidade de Goiânia, em 2014, que gerou um capítulo de um livro recentemente publicado (DUQUE, 2016). Daniela, ainda, foi convidada a falar sobre os encontros e as experiências vivenciadas a partir deles no Campus Pantanal no "V Colóquio de Ciências Sociais da UFMS/CPNV", "VII Jornada Nacional de Educação da UFMS/CPNV" e "IV Seminário de Educação Inclusiva da Rede Municipal de Educação de Naviraí”, que aconteceram em conjunto, simultaneamente, em 2015, no Campus da UFMS em Naviraí. Ademais, contribuiu também como expositora da temática "Homofobia, Lesbofobia e Transfobia" no "Seminário Estadual de Políticas Públicas para Mulheres", realizado pela Subsecretaria de Políticas Públicas para Mulheres de Mato Grosso do Sul (SPPM/MS) em março deste ano de 2016, em Campo Grande.

Essas informações são importantes ao serem apresentadas aqui porque revelam um processo de reflexão coletiva, não somente entre eu (orientador) e a acadêmica (coordenadora do projeto de extensão), mas em um sentido bastante dialogado em todos estes espaços privilegiados para a discussão que trago neste artigo, tanto ligados à universidade como ligados ao governo, e, até mesmo, ao movimento social.

\section{O PÚBLICO E OS EFEITOS DA VISIBILIDADE LOCAL DA AÇÃO}

Tivemos a participação total de trinta e seis pessoas, em quinze encontros, sendo acadêmicas e acadêmicos da UFMS dos cursos de Psicologia, História, Direito, Pedagogia, Letras e de Serviço Social, sendo este último de outra instituição de ensino superior, bem como de docentes da UFMS, também estes profissionais da rede pública de ensino de 
Corumbá e do Instituto Federal, psicólogas e psicólogos, bem como outros profissionais da saúde que também frequentaram algumas reuniões. Com isso, conseguimos uma discussão num âmbito interdisciplinar por conta deste quantitativo e ainda a diversidade de participantes, além dos próprios textos lidos e discutidos que favoreceram as análises de diferentes perspectivas disciplinares.

Além das escutas que tivemos com as pessoas participantes em cada encontro, sete entrevistas realizadas presencialmente pela coordenadora do projeto embasaram empiricamente todas as afirmações contidas neste artigo, que, por sua vez, estão presentes no já citado relatório final produzido por PAIVA (2016). O que sempre nos preocupou foi a baixa adesão somada à baixa assiduidade daquelas e daqueles que, frequentemente nos procuravam uma vez, compareciam ao encontro, demonstravam interesse em voltar, mas não voltavam.

Segundo o que pudemos perceber, parte da falta de adesão ocorreu devido à demanda de trabalhos acadêmicos. Outro ponto citado nas entrevistas foi em relação ao afastamento da unidade I e II do local onde os encontros passaram a ser realizados, isto é, da unidade III, em uma segunda fase do projeto, que ocorreu em 2015, quando imaginamos levar os encontros para um bairro mais acessível à comunidade geral. Também tomamos esta decisão em função da relação estreita que poderia ser estabelecida entre os discentes dos diversos cursos de graduação bem como as acadêmicas e acadêmicos dos mestrados em Educação e Estudos Fronteiriços, visto que desenvolviam e desenvolvem suas atividades nesta unidade.

Mesmo com estas modificações no formato original da proposta do projeto, que teve todos os encontros iniciais realizados na Unidade II, no convívio direto com os cursos de graduação, o número de participantes não aumentou. No entanto, as poucas pessoas assíduas seguiram frequentando as reuniões. Estas, as mais presentes, são de diferentes perfis em termos de raça, classe, idade, gênero e sexualidade. O grupo era bem diversificado.

Outra suposição para essa falta de adesão pode ser atribuída à interpretação errônea de que esse projeto possuía uma falta de institucionalização. Isso surgiu a partir da entrevista feita a um discente, quando se referiu ao aumento na motivação de colegas do seu curso em relação à participação que valeria horas-atividade: “Agora que vale carga horária, acredito que vá encher mais". No entanto, mesmo tendo sido esclarecido que, desde o início, o projeto ofereceria certificados, não ocorreu a esperada participação. Os certificados são importantes para compor horas complementares de atividades acadêmicas necessárias para o cumprimento da carga horária dos cursos. 
DUQUE, T.

$\mathrm{O}$ que me parece mais importante para entender o envolvimento, ou o não envolvimento, do público com o projeto, tem relação direta com a visibilidade, e, em especial, o efeito desta visibilidade na cultura local. As redes sociais (sobretudo o Facebook) potencializaram o alcance da divulgação para outros cursos e comunidade em geral. As pessoas estavam conectadas e muitas, mesmo não frequentando os encontros, sabiam da sua existência e "curtiam" os convites, assim como tinham acesso aos textos.

Segundo o grupo de pessoas participantes, os colegas acadêmicos que estavam de fora perguntavam sobre os dias e quais eram as pessoas que já estavam participando. Depois de certo "mapeamento" do grupo que frequentava as reuniões, um certo número de estudantes davam certeza sobre a sua participação e, inclusive, prometiam levar amigas e amigos. Justificavam o interesse considerando a inexistência da abordagem dessa temática na sua formação, porém, a participação seguiu baixa e começaram a surgir comentários depreciativos quanto à participação das pessoas nos encontros.

Entre as falas que pudemos reunir, destacamos a de três acadêmicas mulheres e jovens. Uma das participantes, quando disse que iria ao encontro no sábado, ouviu de uma amiga em sala de aula: "não toque em mim na segunda-feira!". Outra, ao ter a recusa de uma amiga em acompanhá-la, escutou: “O que o meu marido irá pensar?”. Outra, disse justificando-se: "Não fui porque meu pai não deixou quando soube do tema".

Para enriquecer o debate, citamos abaixo um depoimento interessante. Ele nos permite pensar os efeitos da visibilidade dos encontros de leitura. As pessoas, ao serem questionadas sobre as críticas que ouviam em relação ao conteúdo e aos homens e mulheres participantes, especialmente aos julgamentos direcionados à coordenadora e ao orientador deste projeto, dentre outras, foi dada uma seguinte resposta (perceba que há certa contradição na avaliação de certa pessoa participante em relação ao perfil das pessoas que frequentavam os encontros, porque, apesar de negar que esse seja um dos motivos de baixa adesão, termina a resposta citando exatamente uma referência feita à Daniela, coordenadora do curso):

Vários. A maioria negativo. Que não era um grupo sério, muita curiosidade com relação ao grupo, o que a gente fazia, como eram os encontros, se os textos tinham fundamento, se isso estava me servindo para alguma coisa. E essas pessoas que faziam esses comentários, eu considerava bem inteligentes. Tinham uma preocupação em saber se eu ainda estava seguindo aquele grupo. Me convidaram inclusive para ir para outro grupo de estudos, por ser sim um grupo sério. Acredito que isso tem a ver com o tema 
mesmo, não com as pessoas envolvidas no projeto. Diziam: "Nossa, você está naquele grupo, ele não tem nada a ver com você". "Ah, você agora é amiga dela! Então por que você é amiga da Daniela agora?" (Transcrição de entrevista realizada por Paiva, 2016).

Por isso, percebi que a temática associada ao perfil de parte das alunas e alunos participantes e de quem estava na coordenação e orientação do projeto, além de, em parte, contextualizar a baixa adesão e algumas críticas depreciativas à proposta, também revelava normas e convenções mais amplas que estão em atuação na região fronteiriça Brasil/Bolívia, afinal, especialmente em relação ao professor orientador e a coordenadora da ação, as performances de gênero e a sexualidade tenderam a fugir daquela culturalmente dita adequada: heterossexual e discreta. Além disso, os textos, amplamente divulgados antes dos encontros, foram citados por alguns como sendo um dos motivos de não participação neste projeto, por serem previamente avaliados como "muito difíceis", ou "avançados para iniciantes". O curioso é que, em nenhum dos encontros, as pessoas que estavam presentes, fizeram tal avaliação.

Isso permite pensar que, mais do que a intensidade da leitura, a partir do que já foi exposto até aqui, parece-me importante chamar a atenção para o que os textos discutiam, e alguns dos seus títulos, amplamente divulgados nas redes sociais junto ao convite para que as pessoas pudessem participar dos encontros: "Da finada à europeia: experiências de ser, não permanecer e estar travesti na adolescência" (DUQUE, 2012); "Transitar para onde? monstruosidade, (des)patologização, (in)segurança social e identidades transgêneras” (LEITE JUNIOR, 2012); “A teoria queer e os intersex: experiências invisíveis de corpos des-feitos" (PINO, 2007), entre outros textos disponibilizados para a leitura.

Das pessoas que foram mais assíduas, algumas se referiram, ainda com estranhamento, ao conteúdo dos encontros, pois nunca haviam imaginado que existissem tanta diversidade de gênero e de sexualidade, nem mesmo poderiam imaginar os desdobramentos que essa diversidade causava na sociedade cheia de preconceitos e discriminações históricas. Para ilustrar essa afirmação, cito trechos das entrevistas com duas/dois acadêmicas/os. O primeiro se refere ao que ela/ele tinha acesso antes dos encontros: "Só havia lido a bíblia, Romanos 1:32, assuntos que apareciam na mídia, se homossexualismo era doença ou se era provocado pela sociedade." O segundo trecho demonstra as expectativas com relação à participação dos/as colegas no projeto e os seus preconceitos: 
DUQUE, T.

Primeiro, era saber mais sobre o tema. Segundo, era que vários acadêmicos [...] se interessassem também sobre o grupo. Cumpri em parte, pois não consegui ir a todos os encontros. E na segunda parte, vi necessidade que outros entrassem no grupo e não foi o que aconteceu. Pois eu acho que o senso comum ainda é muito forte, pois mesmo com estudos científicos, não se consegue quebrar o senso comum, a religião ainda é muito forte, os preconceitos também, e não conseguem deixar tudo do lado de fora e entrar na universidade e serem neutros. (Transcrição de entrevista realizada por Paiva, 2016).

É exatamente sobre essas avaliações que os/as participantes/as fizeram dos encontros e da visibilidade deles no contexto local, visibilidade esta que pode ter impactado a baixa adesão das acadêmicas e acadêmicos e da comunidade em geral nos encontros, que me focarei a seguir.

\section{REFLETINDO SOBRE IDENTIDADE, ABJEÇÃO E DIFERENÇA}

Segundo Butler (2003), em nossas sociedades, há uma matriz de inteligibilidade e de reconhecimento de humanidade, a qual opera da seguinte forma: "sexo" 3 feminino = gênero feminino = desejo pelo "sexo oposto"; ou, vice e versa, "sexo" masculino = gênero masculino = desejo pelo "sexo oposto". Podemos avaliar, segundo esta autora, que aquelas e aqueles que "escapam" à esta matriz, são alocados ao universo do "menos humano", isto é, "desumanizado", do abjeto. Em outras palavras, as normas que nos permitem ser reconhecidos como humanos são articuladas socialmente e com variações. E, em certas ocasiões, as mesmas normas que conferem a qualidade de "humano" a certos indivíduos são aquelas que privam os outros da possibilidade de conseguir o mesmo status, produzindo assim um diferencial entre os "humanos" e os "menos humanos". Estas normas têm consequências de largo alcance sobre a nossa concepção do modelo de humano com direitos e do humano que se inclui na esfera na participação da deliberação política (BUTLER, 2006, p. 14).

Contudo, o processo de reconhecimento citado acima, em nada pode significar que há a possibilidade de existir experiências completamente, cem por cento, correspondentes à referida matriz de inteligibilidade. A matriz está aí como um ideal, e, por mais que as pessoas

\footnotetext{
${ }^{3}$ Utilizo a palavra "sexo" entre aspas em um sentido crítico, na tentativa de problematizar qualquer perspectiva bio-naturalizante desta categoria, destacando, portanto, seu caráter sociocultural.
} 
acreditem que ela é perfeitamente cumprida pela dita maioria, isto é, pelos ditos "normais", é importante reconhecer que ela não é. Nesse sentido, deveríamos, conforme sugere Bento (2011), considerar que a humanidade se organiza e se estrutura na e pela diferença.

\begin{abstract}
Se tivermos essa premissa evidente, talvez possamos inverter a lógica: não se trata de identificar "o estranho" como "o diferente", mas de pensar que estranho é ser igual e na intensa e reiterada violência despendida para se produzir o hegemônico transfigurado em uma igualdade natural (Idem, p. 556).
\end{abstract}

No entanto, cabe-nos “[...] considerar as circunstâncias sociais, políticas e históricas da produção da diferença, as relações assimétricas que nortearam e norteiam sua produção e os conjuntos de representações sociais em circulação" (JUNQUEIRA, 2009, p. 399). É nesse sentido que, muitas vezes, é preciso reconhecer que fazemos parte desse processo de deslegitimar os/as diferentes, seja nas práticas de pesquisa ou de ensino, porque, afinal, não estamos acima das normas e convenções sociais, e, como sabemos, as pesquisas e nossas aulas são igualmente experiências culturais demarcadas por nossas concepções de gênero e sexualidade.

Mas, aqui, o que essa experiência de projeto de extensão de fato revela é que eu, assim como a minha orientanda, e algumas pessoas que frequentavam os encontros de leitura, éramos os próprios "diferentes": sinais de uma perigosa "abjeção", isto é, passamos a ser aquelas e aqueles em que se evitava estar para que "o marido" não pudesse pensar mal, nem mesmo éramos dignos de sermos "tocados na segunda-feira", do mesmo modo, éramos os que discutiam temas considerados inapropriados, a ponto do pai de uma acadêmica do campus não autorizá-la participar dos encontros.

As falas das três interlocutoras apresentadas no item anterior e retomadas aqui nos levam a múltiplos entendimentos de parte das normas e das convenções de gênero e sexualidade nos dias de hoje. Além disso, ensinam-nos como elas estão se constituindo na realidade do Campus Pantanal da UFMS. Preocupa-nos o quanto elas parecem visibilizar limites que, evidentemente, influenciam, entre outras coisas, nas dificuldades que temos na busca do fortalecimento dos espaços institucionais de ensino-aprendizado sobre gênero e sexualidade. Além disso, essas falas, de forma indireta, apontam parte dos estigmas associados às vivências das pessoas do contexto local que, segundo as expectativas mais conservadoras, não tem correspondido à matriz de inteligibilidade apresentada acima. 
DUQUE, T.

No entanto, penso que não devemos encarar essas falas como sendo algo revelador de moralidades localizadas apenas em uma cidade do interior, fronteiriça, como se houvesse uma diferença drástica se comparada com cidades maiores ou capitais para além da região de fronteira propriamente dito, ao ponto de existir aqui situações preconceituosas e não lá. Dito de outro modo, não se trata de reforçar com esta crítica o estigma comumente vinculado às regiões fronteiriças, afinal,

a fronteira em seu sentido mais comum está ligada ao preconceito por sua condição de margem, portanto, marginal a uma noção, decorrente de questões históricas e políticas. É um local no qual se pode assimilar a negatividade, atribuída por diversos fatores como o ilícito, a clandestinidade, a miscigenação, entre outros. (OLIVEIRA e CAMPOS, 2012, p. 17).

Um exemplo que serve de contraponto a qualquer possibilidade equivocadamente de estigma em relação à cidade de Corumbá, é o que foi noticiado sobre o acontecido no campus da UFMS da capital do Estado, cidade de Campo Grande, onde, criminosamente, após a realização de uma campanha contra o preconceito sofrido no restaurante universitário por uma acadêmica identificada como transexual, atearam fogo nos livros do Diretório Central dos Estudantes (DCE), entidade que havia tomado a iniciativa contra o ato discriminatório ${ }^{4}$.

Por fim, o contexto em questão dessa baixa frequência aos encontros parece ficar ainda mais complexo pela nossa observação e percepção diante de outras reações que podem ter relação direta com o fato de eu ser uma "bicha declarada", isto é, apesar de não ser um homem efeminado (aos olhos de muitos, mas não de uma totalidade de interlocutores/as), dizer ou expor publicamente minha orientação sexual. Além disso, a acadêmica que coordenou o projeto é reconhecida como uma mulher "muito masculinizada" entre seus colegas do campus, muitos a apontam como sendo a "machorra" (termo pejorativo para as lésbicas na cidade) do campus. A sua masculinidade, inclusive, conforme depoimentos colhidos nos encontros, fez com que as pessoas a identificassem como sendo alguém que só se relaciona afetiva e sexualmente com mulheres, causando surpresas quando ela se declarou bissexual.

Portanto, parece claro que a visibilidade das nossas experiências de gênero e sexualidade, associada ao tema dos encontros, fez com que algumas pessoas não se sentissem à vontade para frequentar as atividades, ou, inclusive, não estarem autorizadas a permanecer,

\footnotetext{
4 Detalhes sobre o acontecimento podem ser lidos em: <http://www.campograndenews.com.br/ladob/comportamento-23-08-2011-08/alunos-reagem-a-homofobia-com-cartazes-fortes-e-sala-acaba-incendiada-naufms>. Acessado em: 09 nov. 2014.
} 
em um determinado período, entre nós. Não podemos generalizar, mas, ainda que a temática pareça assustar mais do que eu e ela, o fato de sermos nós, de gêneros e sexualidades tidas como "diferentes" da maioria, também influenciaria na relação das pessoas com a proposta. Por exemplo, os acadêmicos homens que encontrei e ainda encontro nos aplicativos de celulares de encontros sexuais e afetivos entre homens ${ }^{5}$ nunca aceitaram o convite para participar da atividade, nem mesmo parecem expor suas preferências sexuais publicamente. É como se, para alguns, além do que já foi exposto aqui, ir aos encontros de leitura sobre gênero e sexualidade significaria assumir ou revelar a prática de uma sexualidade não-heterossexual. Isso fica claro em outra fala de uma das pessoas entrevistadas:

Normalmente falam que é por causa de casamento, de marido, é à noite, que por isso não podem participar. Não acredito nisso. Acho que é falta de interesse ou preconceito mesmo. Acho que a questão do assunto, popular, comentado, está em alta, tem medo de ser discriminada de alguma forma, de ter piadinha, pra mim esse grupo teria que abrir mais, arriscar em eventos maiores. (Transcrição de entrevista realizada por Paiva, 2016).

Ainda que, como se pode conferir, a realidade parece revelar-se preconceituosa, no final do fragmento acima parece haver uma indicação propositiva. Com o término do projeto, fica a indicação para a necessidade de ampliação das atividades e o desafio de arriscar-se em eventos maiores, com mais gente. Isso, porém, pode significar que, diferente dos encontros com poucas pessoas, a visibilidade (ou seria invisibilidade?) que um grupo maior daria aos processos de diferenciação em termos de gênero e sexualidade favoreceria um grande envolvimento do público esperado. Dito de outro modo, se todo mundo fosse, a participação não seria uma ameaça à identidade em termos de gêneros e sexualidade, isto é, não estariam tão vulneráveis aos processos de abjeção.

\section{CONSIDERAÇÕES FINAIS}

Como citei na introdução deste texto, a diferença nem sempre é vista como um marcador de hierarquia e opressão. Neste sentido, aquelas pessoas pouco assíduas nos encontros podem ser compreendidas como um importante contraponto a todas as críticas e

\footnotetext{
${ }^{5}$ Esses encontros online estão dentro do contexto de estudos da temática de gênero e sexualidade na fronteira Brasil-Bolívia, estudos estes relacionados a um dos meus projetos de pesquisas atuais.
} 
DUQUE, T.

expectativas negativas ao projeto aqui refletido. Parece que a demarcação identitária daquelas e daqueles que foram aos encontros, não somente a minha e a da coordenadora da ação, foi de grande importância para a promoção de um espaço universitário plural e diverso. Alguns e algumas que se envolveram na ação deixaram claro nos encontros que os efeitos para a sua experiência acadêmica, profissional e pessoal foram grandes, especialmente no sentido de compreenderem a complexidade das produções das diferenças, inclusive aquelas que as envolviam e os envolviam diretamente. Isso se deu, inclusive, a partir da percepção e do reconhecimento das avaliações estigmatizantes e pejorativas por parte das pessoas que não foram, mas avaliaram e julgaram quem participou do projeto.

Por tudo que expus aqui, avalio que a continuidade de ações com esta temática parece urgente na realidade do Campus Pantanal, especialmente se envolver mais acadêmicas e acadêmicos, professoras e professores e a comunidade. Este projeto de extensão, com a participação das pessoas que, de alguma forma, enfrentaram críticas e questionaram regimes de visibilidade que as colocaram sob "suspeita" em relação ao cumprimento de normas e convenções sociais de gênero e sexualidade, nos permitiu compreender a dimensão dos efeitos e dos desafios de incluir esta temática no contexto universitário. Outras ações, com orientação teórica e dinâmicas diversas, certamente contribuirão para a melhor análise dessas questões.

\title{
"DO NOT TOUCH ME ON MONDAY": DIFERENCE, ABJECTION AND IDENTITY IN AN EXTENSION PROJECT, ON PANTANAL CAMPUS OF THE FEDERAL UNIVERSITY OF MATO GROSSO DO SUL
}

\begin{abstract}
This experience report focuses on the extension project "Reading meetings on gender and sexuality", held in the Pantanal Campus of the Federal University of Mato Grosso do Sul, in 2014 and 2015. The action was coordinated by Psychology student, under my guidance. I present, here, the log and the development of the activities, as well as the visibility effects of the meetings in the local context. I discuss, from a post-structuralist point of view, how gender and sexuality, besides being the subject of the project, also help us to evaluate the low attendance of the thirty-six people who sporadically attended the fifteen meetings. Aversion


to abjection, that is, to the not positive recognition of gender and sexuality performances that do not necessarily match the matrix of intelligibility "'sex' = gender $=$ desire", it is seen as an important factor for the evaluation of the experience and of the own cultural context of the Brazil-Bolivia border.

Keywords: Difference; Abjection; Identity; Border; Extension

\title{
"NO ME TOQUES EL LUNES": DIFERENCIA, ABYECCIÓN E IDENTIDAD EN UN PROYECTO DE EXTENSIÓN EN EL CAMPUS PANTANAL DE LA UNIVERSIDAD FEDERAL DE MATO GROSSO DO SUL
}

\begin{abstract}
Resumen
Este relato de experiencia se centra en el proyecto de extensión "Encuentros de lecturas sobre género y sexualidad", realizado en el Campus Pantanal, de la Universidad Federal de Mato Grosso do Sul, en 2014 y 2015. La coordinación de la acción fue de una académica de Psicología, bajo mi orientación. Aquí presento el histórico y el desarrollo de las actividades, así como los efectos de la visibilidad de los encuentros en el contexto local. Discuto, desde un enfoque posestructuralista, cómo las cuestiones de género y sexualidad, más allá de ser temas del proyecto, también nos ayudan a evaluar la baja asistencia de las treinta y seis personas que asistieron de forma esporádica las quince reuniones. La aversión a la abyección, es decir, al no reconocimiento positivo de las actuaciones de género y de las sexualidades que no corresponden necesariamente con la matriz de inteligibilidad “"sexo” = género = deseo", es apuntada como un factor importante para la evaluación de la experiencia y del propio contexto cultural de la frontera Brasil-Bolivia.
\end{abstract}

Palavras clave: Diferencia; Abyección; Identidad; Frontera; Extensión

\section{REFERENCIAIS BIBLIOGRÁFICOS}


DUQUE, T.

BENTO, B. Na escola se aprende que a diferença faz a diferença. Estudos Feministas, Florianópolis, n. 19(2), p. 549-559, 2011.http://dx.doi.org/10.1590/S0104-

026X2011000200016

. A reinvenção do corpo: sexualidade e gênero na experiência transexual. Rio de Janeiro: Garamond, 2006.

BRAH, A. Diferença, diversidade, diferenciação. Cadernos Pagu, n. 26, Campinas-SP, Núcleo de Estudos de Gênero-Pagu/Unicamp, p. 329-376, 2006.

http://dx.doi.org/10.1590/S0104-83332006000100014

BUTLER, Judith. Deshacer el Género. Barcelona, Paidós, 2006.

Problemas de gênero: feminismo e subversão da realidade. Rio de Janeiro:

Civilização Brasileira, 2003.

DUQUE, Tiago. Da finada à europeia: experiências de ser, não permanecer e estar travesti na adolescência. Bagoas: Revista de Estudos Gays, v. 6, p. 173-198, 2012. Disponível em: <http://www.cchla.ufrn.br/bagoas/v06n07art09_duque.pdf>. Acesso em: 20 de mai. 2016.

"A mais bicha" da escola ou como pensar pesquisas sobre gênero e sexualidade na educação. In: FREITAS, R. A. M. M.; LIBÂNEO, J. C. (Org.). Didática e Diversidade. PósGraduação e Pesquisa em Educação: contradições e desafios para a transformação social. 1. ed. Goiânia: Editora da PUC de Goiás, v. 03, p. 104-113, 2016. Disponível em: <http://www.cpgss.pucgoias.edu.br/ArquivosUpload/14/file/Volume\%203\%20\%E2\%80\%93 \%20Did\%C3\%A1tica\%20e\%20diversidade.pdf $>$. Acesso em: 26 de mai. 2016.

FOUCAULT, Michel. História da sexualidade I: A vontade de saber. Rio de Janeiro, Edições Graal, 2007.

JAGOSE, Annamarie. Queer Theory - na introduction. New York: New York University Press, 1996.

JUNQUEIRA, R. D. "Educação e Homofobia: o reconhecimento da diversidade sexual para além do multiculturalismo liberal". In: - (Org.). Diversidade sexual na educação: problematizações sobre homofobia nas escolas. Brasília: Ministério da Educação, Secretaria de Educação Continuada, Alfabetização e Diversidade, UNESCO, p. 367-444, 2009.

Disponível em: 〈http://unesdoc.unesco.org/images/0018/001871/187191por.pdf〉. Acesso em: 10 nov. 2012.

LEITE JUNIOR, Jorge. Transitar para onde? monstruosidade, (des)patologização, (in)segurança social e identidades transgêneras. Estudos Feministas, Florianópolis, 20(2): 256, maio-agosto, p. 559-568, 2012. http://dx.doi.org/10.1590/S0104-026X2012000200016

OLIVEIRA, M. A. M.; e CAMPOS, D. L. Migrantes e Fronteira: lógicas subvertidas, vidas refeitas. In: PEREIRA, J. H. V.; OLIVEIRA, M. A. M. (Orgs.). Migração e Interação resultados de pesquisas em Mato Grosso do Sul. Dourados: Ed. UFGD, 2012. 
PAIVA, Daniela Peño. Relatório final - projeto de extensão "encontro de leitura sobre gênero e sexualidade". Universidade Federal de Mato Grosso do Sul - Campus Pantanal, 2016.

PINO, Nádia Perez. A teoria queer e os intersex: experiências invisíveis de corpos des-feitos. Cadernos Pagu , n. 28, jan-jun, 2007. http://dx.doi.org/10.1590/S0104-83332007000100008

SEIDMAN, Steven. "Introduction”. In: Queer theory/ Sociology. Cambridge, MA, Blackwell, pp. 1-25, 1996.

Data de recebimento: $19 / 07 / 2016$ Data de aceite: 05/09/2016 